\title{
Mild hearing impairment can reduce verbal memory performance in a healthy adult population.
}

Citation for published version (APA):

van Boxtel, M. P. J., van Beijsterveldt, C. E. M., Houx, P. J., Anteunis, L. J. C., Metsemakers, J. F. M., \& Jolles, J. (2000). Mild hearing impairment can reduce verbal memory performance in a healthy adult population. Journal of Clinical and Experimental Neuropsychology, 22, 22-22.

https://doi.org/10.1076/1380-3395(200002)22:1;1-8;FT147

Document status and date:

Published: 01/01/2000

DOI:

10.1076/1380-3395(200002)22:1;1-8;FT147

Document Version:

Publisher's PDF, also known as Version of record

\section{Please check the document version of this publication:}

- A submitted manuscript is the version of the article upon submission and before peer-review. There can be important differences between the submitted version and the official published version of record.

People interested in the research are advised to contact the author for the final version of the publication, or visit the DOI to the publisher's website.

- The final author version and the galley proof are versions of the publication after peer review.

- The final published version features the final layout of the paper including the volume, issue and page numbers.

Link to publication

\footnotetext{
General rights rights.

- You may freely distribute the URL identifying the publication in the public portal. please follow below link for the End User Agreement:

www.umlib.nl/taverne-license

Take down policy

If you believe that this document breaches copyright please contact us at:

repository@maastrichtuniversity.nl

providing details and we will investigate your claim.
}

Copyright and moral rights for the publications made accessible in the public portal are retained by the authors and/or other copyright owners and it is a condition of accessing publications that users recognise and abide by the legal requirements associated with these

- Users may download and print one copy of any publication from the public portal for the purpose of private study or research.

- You may not further distribute the material or use it for any profit-making activity or commercial gain

If the publication is distributed under the terms of Article $25 \mathrm{fa}$ of the Dutch Copyright Act, indicated by the "Taverne" license above, 


\title{
Mild Hearing Impairment Can Reduce Verbal Memory Per- formance in a Healthy Adult Population*
}

\author{
M. P. J. van Boxtel ${ }^{1}$, C. E. M. van Beijsterveldt ${ }^{1}$, P. J. Houx ${ }^{1}$, L. J. C. Anteunis ${ }^{2}$, \\ J. F. M. Metsemakers ${ }^{3}$, and J. Jolles ${ }^{1}$ \\ Departments of ${ }^{1}$ Psychiatry and Neuropsychology, ${ }^{2}$ Otolaryngology, and \\ ${ }^{3}$ General Practice, Maastricht University, The Netherlands
}

\begin{abstract}
We studied to what extent immediate and delayed recall in an auditory verbal learning paradigm was affected by basic information processing speed (digit copying) and hearing acuity (average hearing acuity at 1,2 and $4 \mathrm{KHz}$ at the better ear). A group of 453 individuals in the age between 23 and 82 years with no overt hearing pathology was recruited from a larger study of cognitive aging (Maastricht Aging Study, MAAS). After controlling for age, sex, educational level, and processing speed it was found that a mild to moderate hearing loss predicted lower verbal memory performance. Auditory administered verbal memory tests can underestimate true memory performance, particularly in older individuals with unknown hearing status.
\end{abstract}

Short-term and long-term memory function is generally assessed in clinical practice by using multi-trial word learning tests, such as the Buschke selective reminding paradigm, the Rey Auditory Verbal Learning Test and the California Verbal Learning Test (Lezak, 1995). In such paradigms, series of words are usually presented auditorily and one is asked to recall the words directly after presentation (immediate recall) and again after a fixed period of time (delayed recall). Although it seems obvious that reliable estimates of verbal memory performance can only be obtained in individuals with unimpaired hearing, it is not clear to what extent verbal memory function is compromised by mild hearing impairment. If this association is robust, it may have implications for the use of such tests in clinical practice. The present paper examines this issue in a population-based study sample of community living individuals aged 24 to 81 years.
There is circumstantial evidence that hearing ability plays a role in verbal learning performance. In one study no difference was found between auditory and visual presentation of monosyllabic words on free recall by younger individuals (Brand \& Jolles, 1985). Another study showed that the free recall performance of young adults was slightly better when words were presented auditorily whereas the performance of older individuals (50 years and older) was better when the words were presented visually (Rabbitt, 1990). This difference increased with age. The author suggested that the age-related decline in hearing was the primary mediator of these modality-specific differences in test outcome.

The case for the involvement of hearing loss in auditory learning performance is based upon the notion that the recall of auditorily presented words depends on proper perception of the target words. Pure-tone sensitivity in the frequency

\footnotetext{
* Address correspondence to: M. P. J. van Boxtel, European Graduate School of Neuroscience (EURON), Maastricht University, Department of Psychiatry and Neuropsychology, P.O. Box 616, 6200 MD Maastricht, The Netherlands. E-mail: martin.vanboxtel@np.unimaas.nl Accepted for publication: May 7, 1999.
} 
range of speech $(.5-4 \mathrm{KHz})$ is generally considered the most crucial component of hearing ability. The hearing impairment of older age is characterized by a loss of sensitivity in the higher frequencies (2-4 KHz, Kline \& Scialfa, 1996). This decline proceeds at a rate of $3 \mathrm{~dB}$ per decade under the age of 55 and $9 \mathrm{~dB}$ per decade thereafter. Age differences in speech perception are only minimal after correction for age-related differences in pure-tone sensitivity (Helfer, 1992; Lutman, Gatehouse \& Worthington, 1991; Sommers, 1997).

The ability to understand speech appears to be related to two major factors (Van Rooij \& Plomp, 1992): a loss of sensitivity to high frequencies in the speech spectrum accounts for approximately two thirds of the systematic variance in speech perception tests and another one third of this variance is explained by central auditory factors, more specifically information processing speed and memory capacity (Van Rooij \& Plomp, 1990; 1991). These factors are themselves affected by age (e.g., Van Boxtel et al., 1998). It seems therefore important to incorporate both a measure of information processing speed and other known covariates of cognitive function, such as age and educational level, when the relationship between hearing acuity and verbal memory function is studied in a statistical model (for a discussion on the central role of speed in the age-cognition relationship, see Salthouse, 1992).

In this study the following main questions are addressed. Firstly, to what extent is the outcome of the auditory verbal memory test mediated by a loss of pure-tone sensitivity, and secondly, is the impact of hearing acuity on verbal memory performance mediated by the speed of information processing?

\section{METHOD}

\section{Participants}

The population consisted of 453 participants from a larger study on determinants of cognitive aging, the Maastricht Aging Study (MAAS; Jolles, Houx, van Boxtel, \& Ponds, 1995). Participants were recruited from the Registration Network Family Practices (RNH, Metsemakers, Höppener, Knott- nerus, Kocken, \& Limonard, 1992), a sample frame for research in primary care. Individuals were excluded when evidence of stroke, mental retardation, or chronic neurological pathology (e.g. dementia, epilepsy, parkinsonism, and malignancies related to the central nervous system) was present in the RNH patient records. Participants were stratified for three demographic variables that are known to be related to cognitive outcome measures: Age (12 levels, ranging from $25 \pm 1$ year, 30 \pm 1 year, ..., to $80 \pm 1$ year), Sex, and level of General Ability ( 2 levels, based on educational level and achievement in professional life; Van Berkel $\&$ Tax, 1990). In total 676 individuals were available for participation in the study. Of the latter group who was contacted by telephone 475 individuals completed the test program: 28 respondents did not meet the exact age criteria, 81 withdrew and 92 were excluded for different reasons (chronic use of psychoactive medication 35, status incompatible with cognitive testing 14, Mini-Mental State Examination (MMSE); Folstein, Folstein, $\&$ McHugh, 1975) score below cutoff 13, recent cerebrovascular disease 8 , other reasons 22). Data from 13 participants who used a hearing aid in one or both ears were not included in this analysis, and nor were the incomplete data from 9 participants, leaving 453 complete cases (Table 1). For a full description of the study sample see Jolles et al. (1995).

\section{Measurements}

Participants were asked by means of questionnaire whether they had hearing problems in daily life ('Can you hear well (if necessary and applicable, with the use of a hearing aid)?' [yes/no]). Educational level was indexed on an 8-point scale, ranging from primary school (1) to higher vocational training and university degree (8) (Jolles et al., 1995). This measure was used in further analyses to control for the effects of schooling on cognitive parameters.

\section{Cognitive assessment}

General information processing speed (Speed) was assessed with the paper-and-pencil Letter-Digit Symbol Test, a modified version of the Symbol Digit Modalities Test (Smith, 1968). Participants are asked to copy numbers in cells that are indexed by a letter. The letter refers to nine letter-number pairs in the key at the top of the form. Outcome is the total number of correctly copied numbers within 90 seconds.

Measures of verbal memory were derived from the Auditory Verbal Learning Test (Brand \& Jolles, 1985), which evaluates the ability to ac- 


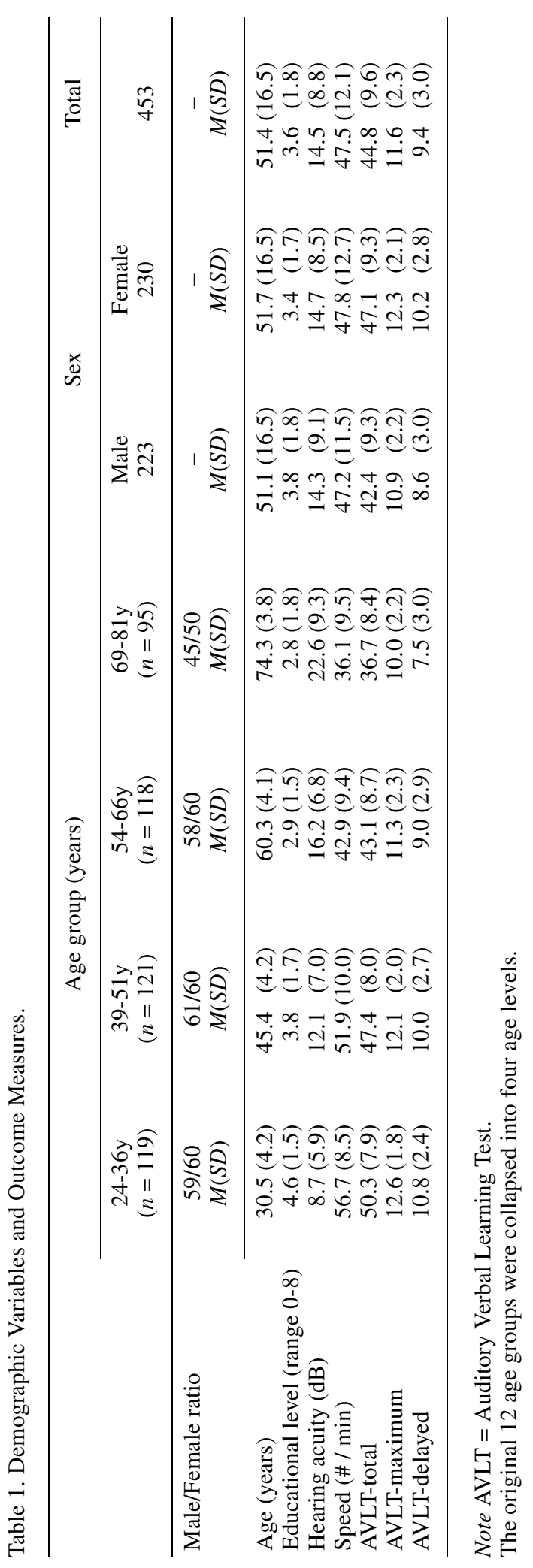


quire and retain novel verbal information. A set of fifteen frequently used monosyllabic words is presented to the participant in each of five subsequent trials. One is asked to reproduce all memorized words immediately after each trial and again 20 minutes after the last trial. Both the sum of correctly reproduced words (AVLT-tot) and the maximum score in five trials (AVLT-max) are recorded as measures of immediate recall. The score after 20 minutes is an estimate of delayed recall capacity (AVLT-del). For this test the target words were pronounced by a professional speaker in a digital recording studio. Words were presented with a high-fidelity stereo speaker system connected to a microcomputer. The volume of the audio system was set to optimal level for each participant and was kept constant for the duration of the test session.

\section{Hearing acuity}

Pure-tone air conduction thresholds were measured in $\mathrm{dB}$ for each ear at .5-1-2 and $4 \mathrm{KHz} \mathrm{Hz}$, using a screening audiometer (Interacoustics AS7, Denmark). The overall hearing acuity was expressed as the average of hearing thresholds at 1,2 and $4 \mathrm{KHz}$ for the better ear, according to recommendations for the assessment of hearing handicap
(Davis, 1995). In the Netherlands, the mean hearing loss has to be $35 \mathrm{~dB}$ or more in the better ear before a person can qualify for a hearing aid paid for by health insurance.

\section{Data analysis}

Nonlinear trends in the data were identified in order to perform linear regression modelling. Existing quadratic effects of age on hearing acuity (Fig. 1 ), speed, and memory variables were included in the regression models as the residual of agesquared $\left(\mathrm{Age}^{2}\right.$-res) after the removal of the linear age component in this term. This procedure is necessary to make age and age-squared orthogonal, thereby avoiding collinearity of these variables (Earles, Connor, Smith, \& Park, 1997). The experimental model described in Figure 2 was broken up in three subsequent steps. In Model 1 the predictive value of Age, $\mathrm{Age}^{2}$-res, Education, and Sex for the factor Speed was tested in a regression analysis, which calculated a residual score for Speed (Speed-res). The same procedure was followed in Model 2 in which hearing acuity served as the outcome measure. The Speed-res variable was then forced into the model to test the additional contribution of Speed to hearing acuity. Next, the calculated residual values of Speed and

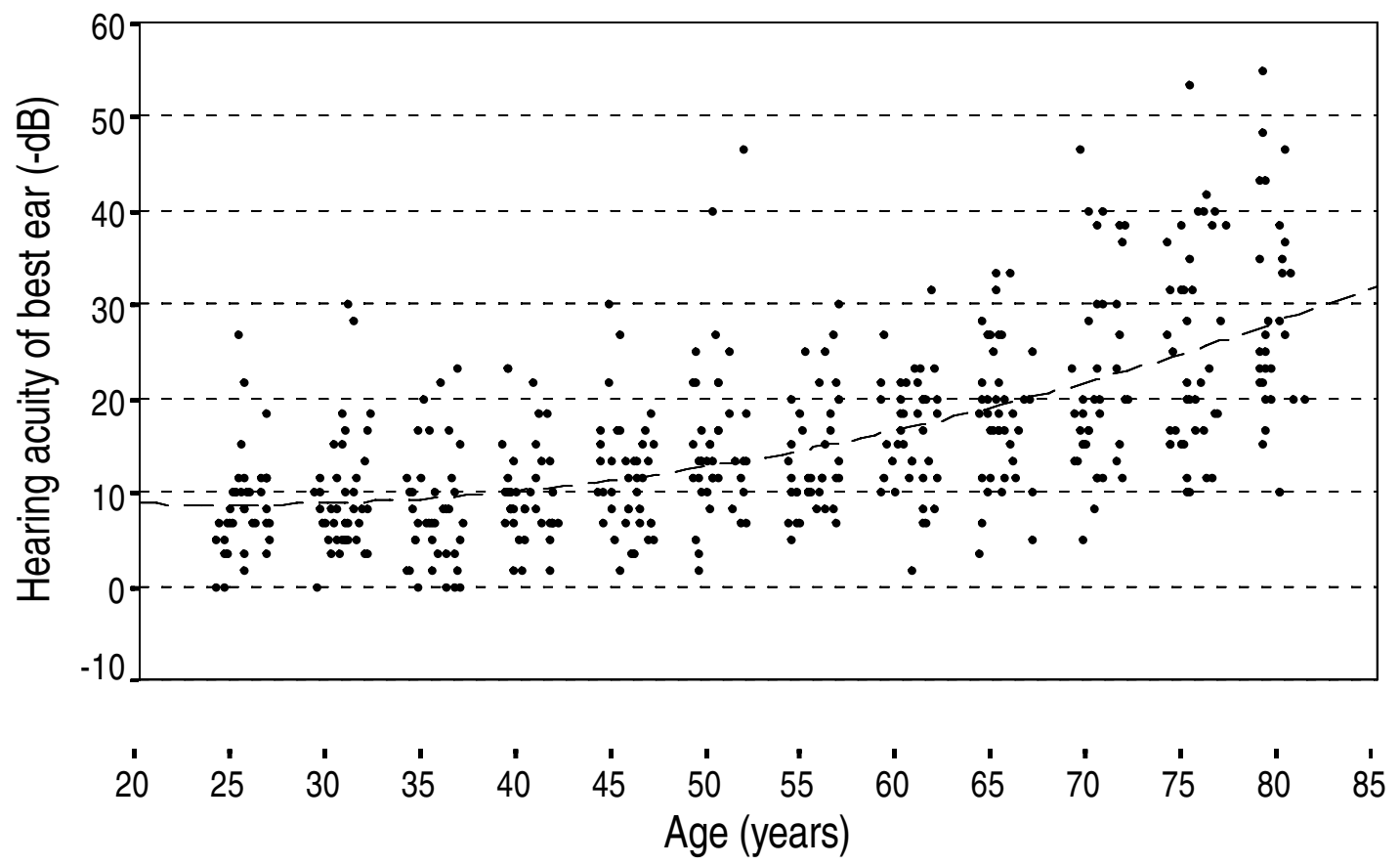

Fig. 1. Hearing acuity as a function of age. The fit $\left(R^{2}\right)$ of the quadratic regression function is .395 . 


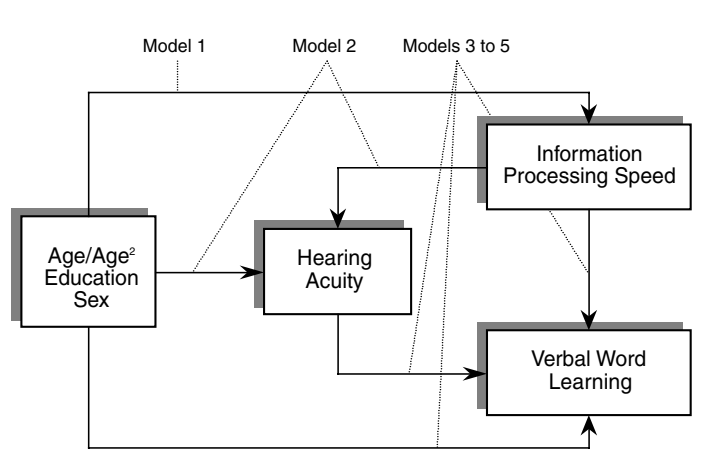

Fig. 2. Overall model that was tested in discrete steps using multiple regression analysis (Model 1 to 5), as is described in the text. In this model hearing acuity, information processing speed, and demographic variables were linked to verbal word learning performance. $\mathrm{Age}^{2}$ indicates the quadratic component of the age effect.

hearing acuity were tested in the final Models 3, 4, and 5 as predictors of word learning performance (AVLT-tot, AVLT-max, and AVLT-del, respectively). Again, the calculation of residual scores for Speed and hearing acuity and their subsequent use as predictors instead of the original variables was done to assure sufficient statistical independence of predictor variables in the final regression models.

In all stages of the analysis the residual scores after regression were inspected for systematic trends, but none were identified.

\section{RESULTS}

Table 1 displays demographic information about the study population and descriptive statistics of variables that were used in the analyses. Zeroorder correlations between predictors and outcome variables are presented in Table 2. Relatively strong negative associations were found between Age and cognitive measures (range -.41 to -.66) and between Hearing Acuity and cognitive variables (range -.36 to -.43 for AVLT variables, -.46 for Speed, respectively). Information processing speed (Speed) was associated with memory performance (range .44 to $.53)$.

Speed was used as the dependent measure in Model 1. Forty-nine percent of the variance in Speed was explained by the variables Age, $\mathrm{Age}^{2}$-res (residual of $\mathrm{Age}^{2}$, after regression of Age on $\mathrm{Age}^{2}$ ), Sex, and Educational level. The contribution of Sex was not significant (Table 3).

The residual value of Speed derived from the regression analysis of Model 1 was entered in Model 2 for Hearing Acuity, after the introduction of the same demographic variables used in Model 1 in the first step of the analysis. Speedres did not explain additional variance in step 2 , which indicates that, after control for demographic characteristics, there was no relationship between information processing speed and hearing ability.

Table 2. Zero-Order Correlations (Pearson) Between Untransformed Variables that Were Included in the Regression Models $(N=453)$.

\begin{tabular}{|c|c|c|c|c|c|c|c|c|c|}
\hline Variable & 1 & 2 & 3 & 4 & 5 & 6 & 7 & 8 & 9 \\
\hline 1. Age & - & & & & & & & & \\
\hline 2. $\mathrm{Age}^{2}$ & .99 & - & & & & & & & \\
\hline 3. Sex & .02 & .02 & - & & & & & & \\
\hline 4. Educational level & -.40 & -.38 & -.11 & - & & & & & \\
\hline 5. Speed & -.66 & -.66 & .03 & .46 & - & & & & \\
\hline 6. Hearing acuity & .58 & .59 & .02 & -.32 & -.46 & - & & & \\
\hline 7. AVLT-tot & -.51 & -.52 & .24 & .31 & .53 & -.43 & - & & \\
\hline 8. AVLT-max & -.41 & -.42 & .29 & .23 & .45 & -.37 & .90 & - & \\
\hline 9. AVLT-del & -.41 & -.42 & .27 & .20 & .44 & -.36 & .82 & .79 & - \\
\hline M & 51.4 & 2915.9 & - & 3.6 & 47.5 & 14.5 & 44.8 & 11.6 & 9.4 \\
\hline (SD) & $(16.5)$ & $(1725.0)$ & - & $(1.8)$ & $(12.1)$ & $(8.8)$ & $(9.6)$ & $(2.3)$ & (3.0) \\
\hline
\end{tabular}

Note $r \leq .03, p=$ not significant; $r=-.11, p=.01$; all other $r$ 's, $p \leq .001$. 
Table 3. Results of Regression Analysis in Separate Models for Speed, Hearing Acuity and Auditory Verbal Learning Performance.

\begin{tabular}{|c|c|c|c|c|c|c|c|c|c|c|}
\hline \multirow[b]{2}{*}{ Step } & \multicolumn{2}{|c|}{ Model 1 Speed } & \multicolumn{2}{|c|}{$\begin{array}{c}\text { Model } 2 \text { Hearing } \\
\text { Acuity }\end{array}$} & \multicolumn{2}{|c|}{ Model 3 AVLT-tot } & \multicolumn{2}{|c|}{ Model 4 AVLT-max } & \multicolumn{2}{|c|}{ Model 5 AVLT-del } \\
\hline & $B$ & $(S E)$ & $B$ & $(S E)$ & $B$ & $(S E)$ & $B$ & $(S E)$ & $B$ & $(S E)$ \\
\hline 1. Age & -.415 & $(.027)^{* * *}$ & .287 & $(.022)^{* * *}$ & -.263 & $(.023)^{* * *}$ & -.049 & $(.006)^{* * *}$ & -.070 & $(.007)^{* * *}$ \\
\hline $\mathrm{Age}^{2}$-res & -.004 & $(.002)^{*}$ & .005 & $(.001)^{* * *}$ & -.005 & $(.001)^{* *}$ & -.001 & $(.000)^{* *}$ & -.001 & $(.000)$ \\
\hline Sex & 1.581 & $(.822)$ & .003 & $(.663)$ & 5.202 & $(.698)^{* * *}$ & 1.415 & $(.174)^{* * * *}$ & 1.709 & $(.238)^{* * *}$ \\
\hline Education & 1.672 & $(.252)^{* * *}$ & -.576 & $(.204)^{* *}$ & .914 & $(.214)^{* * *}$ & .173 & $(.054)^{* *}$ & .138 & $(.073)$ \\
\hline 2. Speed-res & & & -.067 & $(.038)$ & .223 & $(.040)^{* * *}$ & .050 & $(.010)^{* * *}$ & .067 & $(.014)^{* * *}$ \\
\hline 3. HA-res & & & & & -.151 & $(.050)^{* *}$ & -.041 & $(.012)^{* *}$ & -.050 & $(.017)^{* *}$ \\
\hline Step & $R^{2}$ & $\left({ }^{\Delta} R^{2}\right)$ & $R^{2}$ & $\left({ }^{\Delta} R^{2}\right)$ & $R^{2}$ & $\left({ }^{\Delta} R^{2}\right)$ & $R^{2}$ & $\left({ }^{\Delta} R^{2}\right)$ & $R^{2}$ & $\left({ }^{\Delta} R^{2}\right)$ \\
\hline 1. & .491 & $(.491)^{* * *}$ & .366 & $(.366)^{* * *}$ & .363 & $(.363)^{* * *}$ & .282 & $(.282)^{* * * *}$ & .256 & $(.256)^{* * * *}$ \\
\hline 2. & & & .371 & $(.005)$ & .403 & $(.040)^{* * *}$ & .319 & $(.037)^{* * * *}$ & .294 & $(.038)^{* * * *}$ \\
\hline 3. & & & & & .416 & $(.013)^{* *}$ & .335 & $(.016)^{* *}$ & .307 & $(.013)^{* *}$ \\
\hline
\end{tabular}

Note $\mathrm{HA}=$ hearing acuity, ${ }^{\Delta} R^{2}=R^{2}$-change.

${ }^{*} p \leq .05 ;{ }^{* *} p \leq .01 ;{ }^{* * *} p \leq .001$

Displayed in the top half are regression coefficients $B$ and $(S E)$ in the final models, and in the bottom half the total $R^{2}$ (and significance of $R^{2}$-change), after entry of the block of demographic variables Age to Education in step 1 (Models 1 to 5), residual Speed in step 2 (Models 2 to 5) and Hearing Acuity in step 3 (Models 3 to 5).

In models 3 to 5 the relationships were tested between Hearing Acuity and AVLT performance, after removal of the variance related to demographic variables in step 1 and Speed-res in step 2. Demographic variables accounted for $26 \%$ (AVLT-del) to 36\% (AVLT-tot) of the variance in performance of the memory tests. Four percent of the variance in these measures was additionally explained by Speed-res in step 2 of the analysis. This indicates that higher information processing speed was associated with better memory performance, independent of demographic variables. Finally, when the residual score of Hearing Acuity that was derived from Model 2 was entered in step 3, an increase in explained variance was observed of $1.3 \%$ for AVLT-tot and AVLT-del, and $1.6 \%$ for AVLTmax. Lower levels of Hearing Acuity were associated with lower AVLT performance.

In an additional analysis, the Age by Hearing Acuity interaction term was tested in step 4 of Models 3 to 5 (results not shown). This was done to test if the Hearing Acuity effect was modified by age level. However, no such interaction was found, indicating that the association between Hearing Acuity and AVLT-performance was not age-dependent.
To put these findings in a more clinical perspective: based on the regression coefficients in Table 3, one may conclude that the predictive value of a $10 \mathrm{~dB}$ loss in hearing acuity was comparable in size to that of being $5.7,8.4$, or 7.1 years 'cognitively older' (Models 3 to 5, respectively), after correction for all background variables.

\section{DISCUSSION}

Pure tone hearing loss was negatively associated with immediate and delayed recall in the verbal memory test in our normal aging population sample. This association was found even though test conditions were optimized by adapting the volume at which target words were presented to adjust for individual hearing ability and by minimizing the background noise in order to rule out measurement error (Helfer, 1992; Van Rooij \& Plomp, 1992).

These findings suggest that verbal memory function may be underestimated in individuals with mild to moderate degree of hearing loss. In clinical settings where age-based norms for neuropsychological tests are used, this can lead to misclassification of individuals with putative 


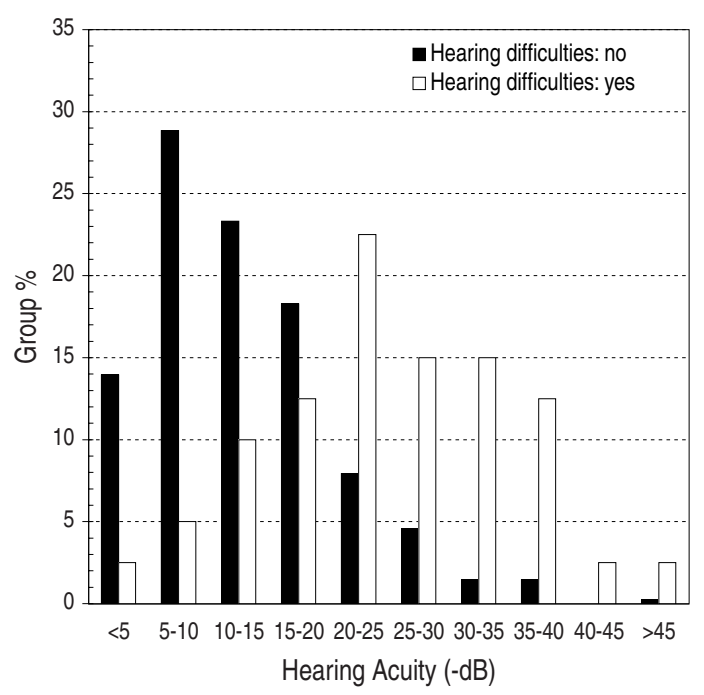

Fig. 3. Proportional histogram of hearing acuity for individuals who report hearing difficulties ( $n$ $=39)$ and those who do not $(n=414)$.

cognitive disorders, such as dementia, particularly in the early stages when it is important to distinguish between depression and age-consistent memory impairment. For example, based on our model the maximum score for delayed recall in an individual aged 60 years with a $30-\mathrm{dB}$ pure-tone hearing loss was statistically comparable to that of someone aged 85 years with normal hearing (all other variables in the model being equal). Moreover, it should be noted that our sample may represent an elite sample from the general population with respect to both hearing and cognitive ability and therefore the true associations between hearing ability and verbal memory may be even stronger than were found in this study. We feel that such observations emphasize the need to evaluate the auditory function of any patient with potential hearing loss before definite conclusions are drawn from the results of verbal memory tests.

Figure 3 indicates that reported complaints about hearing loss may provide some indication of an existing hearing dysfunction. The hearing acuity of individuals with hearing problems in this sample $(n=39)$ was on average $12.5 \mathrm{~dB}$ lower than that of individuals without hearing problems $(M=25.9 \mathrm{~dB}[S D=10.1]$ and $M=$
$13.4 \mathrm{~dB}[S D=7.8]$, respectively; $p<.001)$. However, there was a large overlap in the distribution of hearing acuity between the two groups.

We included a measure of information processing speed in Models 3 to 5 as a central mediator of both hearing acuity and memory function. Although other cognitive abilities may potentially contribute to the outcome on LDST performance, we expect that auditory function as measured in this study can only be affected by the time needed for central stimulus processing and much less by other cognitive processes that load on the speed score (Model 2).

Speed independently explained up to $4 \%$ of the variance in memory performance scores. However, the effect of Speed on memory function was not mediated by Hearing Acuity. This observation may indicate that the central component of hearing acuity (mediated by neural structures beyond the cochlea), as proposed in earlier studies, is implicated less in verbal memory performance than the peripheral component (anatomical structures in the middle and inner ear). Conceivably, the effects of information processing speed in the models of verbal memory function (3 to 5) were to some extent overestimated as other cognitive processes than 'central' speed alone may have been implicated in the speedmemory relationship. Nevertheless, this is an interesting finding in the light of previous findings of negative associations between moderate hearing loss and the score on the Mini-Mental State Examination, a broad cognitive screening instrument, in an older population of mixed dementia status (Uhlmann, Larson, Rees, Koepsell, \& Duckert, 1989a; Uhlmann, Teri, Rees, Mozlowski, \& Larson, 1989b). Indeed, some evidence exists that a hearing impairment may reduce adult intellectual performance over time (Sands \& Meredith, 1989). The present sample did not include individuals with overt cognitive disorders (Jolles et al., 1995). Our sample will be followed up after 6 years as part of the MAAS program. This will enable us to test the hypothesis that in a normal aging population a central component of hearing acuity is associated with verbal memory function.

In conclusion, this study demonstrates that the outcome of verbal learning tests must be in- 
terpreted with caution in individuals with mild to moderate hearing loss. If the exact deficit can be determined by pure-tone audiometry, then adjustment of the individual's age in age-specific norm tables seems justified. However, if normative values are based on older individuals of unknown auditory status, then this procedure may not be acceptable. In future studies the issue needs to be addressed if well-standardized visual verbal learning tests are less affected by age-related sensory impairment. If so, such tests may resolve some of the above-mentioned difficulties in the interpretation of test results in individuals with a hearing impairment.

\section{REFERENCES}

Brand, N., \& Jolles, J. (1985). Learning and retrieval rate of words presented auditory and visually. Journal of General Psychology, 112(2), 201-210.

Davis, A. (1995). Hearing in adults. Nottingham: Whurr Publishers.

Earles, J. L., Connor, L. T., Smith, A. D., \& Park, D. C. (1997). Interrelations of age, self-reported health, speed, and memory. Psychology and Aging, 12(4), 675-683.

Folstein, M. F., Folstein, S. E., \& McHugh, P. R. (1975). Mini Mental State. Journal of Psychiatric Research, 12, 189-198.

Helfer, K. S. (1992). Aging and the binaural advantage in reverberation and noise. Journal of Speech and Hearing Research, 35(6), 1394-1401.

Jolles, J., Houx, P. J., van Boxtel, M. P. J., \& Ponds, R. W. H. M. (Eds.). (1995). Maastricht Aging Study: Determinants of cognitive aging. Maastricht: Neuropsych Publishers.

Kline, D. W., \& Scialfa, C. T. (1996). Visual and auditory aging. In J. E. Birren \& K. W. Schaie (Eds.), Handbook of the psychology of aging, (4th ed., Vol. 2, pp. 181-203). San Diego, CA: Academic Press.

Lezak, M. D. (1995). Neuropsychological Assessment. (3rd ed.). New York: Oxford University Press.

Lutman, M. E., Gatehouse, S., \& Worthington, A. G. (1991). Frequency resolution as a function of hearing threshold level and age. Journal of the Acoustical Society of America, 89(1), 320-328.

Metsemakers, J. F. M., Höppener, P., Knottnerus, J. A., Kocken, R. J. J., \& Limonard, C. B. G. (1992). Computerized health information in the Netherlands: A registration network of family practices. British Journal of General Practice, 42, 102-106.
Rabbitt, P. (1990). Mild hearing loss can cause apparent memory failures which increase with age and reduce with IQ. Acta Otolaryngol Suppl Stockh, 476(167), 167-175.

Salthouse, T. A. (1992). Mechanisms of age-cognition relations in adulthood. Hillsdale, NJ: Lawrence Erlbaum Associates.

Sands, L. P., \& Meredith, W. (1989). Effects of sensory and motor functioning on adult intellectual performance. Journal of Gerontology, 44, P56-58.

Smith, A. (1968). The Symbol Digit Modalities Test: A neuropsychological test for economic screening of learning and other cerebral disorders. Learning Disorders, 36, 83-91.

Sommers, M. S. (1997). Speech perception in older adults: the importance of speech-specific cognitive abilities. Journal of the American Geriatrics Society, 45(5), 633-637.

Uhlmann, R. F., Larson, E. B., Rees, T. S., Koepsell, T. D., \& Duckert, L. G. (1989a). Relationship of hearing impairment to dementia and cognitive dysfunction in older adults. Jama, 261(13), 1916-9.

Uhlmann, R. F., Teri, L., Rees, T. S., Mozlowski, K. J., \& Larson, E. B. (1989b). Impact of mild to moderate hearing loss on mental status testing. Comparability of standard and written Mini-Mental State Examinations. Journal of the American Geriatrics Society, 37(3), 223-228.

Van Berkel, A. B., \& Tax, B. (1990). Naar een standaardoperationalisatie van sociaal-economische status voor epidemiologisch en sociaal-medisch onderzoek [Towards a standard operationalization of socio-economical status for epidemiological and socio-economical research]. Den Haag: Ministerie van Welzijn, Volksgezondheid en Cultuur.

Van Boxtel, M. P. J., Buntinx, F., Houx, P. J., Metsemakers, J. F. M., Knottnerus, J. A., \& Jolles, J. (1998). The relation between morbidity and cognitive performance in a normal aging population. Journal of Gerontology, 53A(2), M146-M154.

Van Rooij, J. C., \& Plomp, R. (1992). Auditive and cognitive factors in speech perception by elderly listeners. III. Additional data and final discussion [comment]. Journal of the Acoustical Society of America, 91(2), 1028-1133.

Van Rooij, J. C. G. M., \& Plomp, R. (1990). Auditive and cognitive factors in speech perception by elderly listeners. II: Multivariate analyses. Journal of the Acoustical Society of America, 88(6), 26112624.

Van Rooij, J. C. G. M., \& Plomp, R. (1991). Auditive and cognitive factors in speech perception by elderly listeners. Acta Otolaryngol (Stockh), 476 (Suppl), 177-181. 